Artículo

\title{
Control biológico de Lasiodiplodia theobromae y Fomitopsis meliae causantes de la muerte regresiva de los cítricos
}

\author{
Laura Glenys Polanco-Florián ${ }^{1,2}$ \\ Omar Guadalupe Alvarado-Gómez ${ }^{1}$ \\ Emilio Olivares-Sáenz ${ }^{1}$ \\ Ramiro González-Garza ${ }^{3}$ \\ Orquídea Pérez-González ${ }^{1 \S}$
}

${ }^{1}$ Universidad Autónoma de Nuevo León. Av. Universidad s/n, Ciudad Universitaria, San Nicolás de los Garza, Nuevo León. CP. 66455. (omaralvarado085@gmail.com; emolivares@gmail.com). ${ }^{2}$ Instituto Dominicano de Investigaciones Agropecuarias y Forestales. Calle Rafael Augusto Sánchez No. 89, Ensanche Evaristo Morales, Santo Domingo, República Dominicana. (polancolaura7@gmail.com). ${ }^{3}$ Biociencia SA de CV. Monterrey, Nuevo León. (biociencia01@ prodigy.net.mx).

${ }^{\S}$ Autora para correspondencia: orquideapg@ hotmail.com.

\section{Resumen}

La investigación fue realizada en el estado de Nuevo León, México, durante el año 2018, con el objetivo de aislar e identificar cepas de microorganismos de suelo y evaluar su capacidad antagónica in vitro frente a los patógenos de cítricos Lasiodiplodia theobromae y Fomitopsis meliae. Para el aislamiento de los microorganismos se realizaron 17 muestreos de rizósfera en diferentes localidades y tipos de vegetación; las muestras se trataron con calor y se sembraron por extensión en el medio de cultivo papa dextrosa agar adicionado con $0.3 \%$ de extracto levadura y $0.3 \%$ de extracto de malta (PDLMA). Los aislamientos obtenidos se evaluaron preliminarmente por observación y confrontación del crecimiento. De 70 cepas aisladas, 15 presentaron actividad antagónica, las cuales mostraron porcentajes de inhibición de 39-91\%. Las cepas de los actinomicetos M4 R y M1-101, y el hongo M104 (Penicillium citrinum) causaron inhibición de 84, 91 y $85 \%$ respectivamente contra $L$. theobromae y de 83,91 y $91 \%$ respectivamente contra $F$. meliae. Se logró el aislamiento de bacterias, actinomicetos y hongos del suelo capaces de inhibir el crecimiento de los hongos $L$. theobromae y $F$. meliae causantes de muerte regresiva de los cítricos.

Palabras clave: Fomitopsis meliae, Lasiodiplodia theobromae, antagonismo, inhibición.

Recibido: febrero de 2020

Aceptado: mayo de 2020 


\section{Introducción}

Los cítricos (Citrus spp.) son considerados como la fruta universal ya que están presentes en más de 100 países y son el grupo de frutas más importante económicamente, abarcando $20 \%$ del mercado mundial de frutas. Actualmente, la mayor parte de la cosecha de cítricos proviene de 10 países que aportan $77 \%$ de la producción, de los cuales China y Brasil producen 42\% y México ocupa la cuarta posición después de los EE. UU. (Lerma et al., 2015).

Las enfermedades constituyen un factor limitante en la producción de estos cultivos en las zonas productoras de México, causadas por alrededor de 50 patógenos que provocan diversos síntomas tales como gomosis, agrietamiento, caída de frutos, mancha grasienta, roña, muerte de ramas, entre otros (Orozco et al., 2013). El hongo Lasiodiplodia spp., ha sido reportado como causante de muerte regresiva y otros síntomas en cítricos y en una amplia gama de cultivos en diversos países (Adesemoye et al., 2014; Rodríguez et al., 2016).

Recientemente Polanco et al. (2019) reportaron a Lasiodiplodia theobromae y Fomitopsis meliae como los hongos causantes de la muerte regresiva de los cítricos en árboles de huertos de los estados de Nuevo León y Tamaulipas, México. Por lo general, el método de control de este hongo es mediante aplicaciones de fungicidas sintéticos. Los fungicidas químicos pueden producir efectos colaterales como la resistencia en plagas y enfermedades, la reducción de las poblaciones de microorganismos benéficos y la contaminación del ambiente (Adeniyi et al., 2013; Tovar et al., 2013; Álvarez, 2015).

Los agentes utilizados para biocontrol reducen significativamente las poblaciones de fitopatógenos y con su uso se pretende equilibrar las perturbaciones ecológicas provocadas por los agroquímicos (Badii y Abreu, 2006) mediante diversos mecanismos como la producción de toxinas (Carisse et al., 2001), la competencia por nutrientes y espacio (Mutawila et al., 2011), inhibición del crecimiento micelial del patógeno y micoparasitismo (Cheng et al., 2012).

Entre los grupos de microorganismos utilizados para biocontrol se encuentran los actinomicetos, los cuales han sido ampliamente estudiados por su capacidad de producir compuestos antibióticos y antifúngicos (Lee et al., 2002), especialmente contra fitopatógenos de importancia agrícola (Sreevidya y Gopalakrishnan 2012; Abdallah et al., 2013; Dávila et al., 2013). Los actinomicetos son bacterias Gram positivas, halladas generalmente en suelo, ríos, lagos, material orgánico en descomposición, entre otros lugares. Muchos son saprofitos y algunas especies son patógenas (Quiñones et al., 2016), como Streptomyces scabiei causante de la sarna común del cultivo de papa.

Desde hace varias décadas, el número de actinomicetos utilizados en la agricultura ha estado en constante aumento como un medio para controlar o reducir las poblaciones de fitopatógenos (Dávila et al., 2013). Aunque los microorganismos han sido estudiados ampliamente en el control de hongos fitopatógenos, son pocos los trabajos realizados en el control de los hongos Lasiodiplodia theobromae y Fomitopsis meliae. Sajitha y Florence (2013); Kamil et al. (2018), evaluaron la capacidad antagónica de actinomicetos para el control de Lasiodiplodia theobromae causantes de daño a la madera del árbol de caucho y la muerte regresiva de plantas de mango respectivamente, con buenos resultados; además Caro et al. (2019) trabajando con actinomicetos obtuvieron resultados promisorios para el control de Lasiodiplodia sp., en el cultivo de papa. 
Aun así, es poco lo que se conoce de trabajos de control de los principales hongos causantes de la muerte regresiva de los críticos, Lasiodiplodia theobromae y Fomitopsis meliae, a los cuales se trata normalmente con el uso de productos químicos o practicas sanitarias del cultivo (podas). Por lo anterior, el objetivo de este trabajo fue aislar cepas de microorganismos de suelo y evaluar su capacidad antagónica in vitro frente a los fitopatógenos Lasiodiplodia theobromae y Fomitopsis meliae, causantes de la muerte regresiva de los cítricos.

\section{Materiales y métodos}

\section{Cepas fúngicas fitopatógenas}

Las cepas fúngicas Lasiodiplodia theobromae y Fomitopsis meliae fueron proporcionadas por la Facultad de Agronomía de la Universidad Autónoma de Nuevo León (FAUANL).

\section{Aislamiento de microorganismos del suelo}

Se realizaron 17 muestreos de suelo con diferentes tipos de vegetación en zonas del estado de Nuevo León (Cuadro 1), se colectaron muestras de la rizósfera a una profundidad de 10 a $15 \mathrm{~cm}$, después de eliminar la capa superficial. Para el muestreo se seleccionaron al azar cinco puntos diferentes para formar una muestra. Las muestras se colocaron en bolsas de plástico, se sellaron y almacenaron en el laboratorio en condiciones de clima fresco.

Cuadro 1. Relación de lugares de muestreo y tipo de vegetación predominante.

\begin{tabular}{ccc}
\hline Localización & Coordenadas & Tipo de vegetación \\
\hline FAUANL, Campus Marín, & $25^{\circ} 52^{\prime}$ 25.76” latitud norte; $100^{\circ} 33^{\prime}$ & $\begin{array}{c}\text { Cultivo de cítricos y } \\
\text { terreno baldío }\end{array}$ \\
municipio Marín & $21.25^{\prime \prime}$ latitud oeste & Cultivo de ajo \\
FAUANL, Campus La & $24.32^{\circ}$ latitud norte; & \\
Ascensión, municipio Aramberri & $99.91^{\circ}$ latitud oeste & \\
Municipio de Mina & $25^{\circ} 52^{\prime}$ a $26^{\circ} 44^{\prime}$ latitud norte; $100^{\circ}$ & Plantas silvestres \\
& $26^{\prime}$ a $101^{\circ} 13^{\prime}$ latitud oeste & \\
\hline
\end{tabular}

Un gramo de cada muestra se disolvió en $9 \mathrm{~mL}$ de agua destilada estéril. Las diluciones fueron tratadas con calor $\left(50{ }^{\circ} \mathrm{C}\right)$ durante $10 \mathrm{~min}$. De cada suspensión se prepararon diluciones seriales 1:100, 1:1 000 y 1:10 000. De cada dilución se transfirieron $100 \mu \mathrm{L}$ a cajas Petri con agar papa dextrosa adicionado con extracto de levadura $(0.3 \%)$ y extracto de malta $(0.3 \%)$ (PDLMA) mediante el método de extensión. Las cajas Petri se incubaron a $25 \pm 2^{\circ} \mathrm{C}$. Se aislaron y purificaron microorganismos que presentaron halos de inhibición (Oskay et al., 2004).

\section{Caracterización morfológica y genética de actinomicetos y bacterias con actividad antagónica}

Las cepas de actinomicetos se identificaron de acuerdo con sus características de crecimiento macroscópicas (forma, color del micelio aéreo, textura y la producción de pigmentos en el medio de cultivo). Adicionalmente, se realizaron observaciones microscópicas utilizando para ello la tinción de Gram. Para la identificación de las bacterias se consideraron forma, color y textura de las colonias, para la visualización microscópica se utilizó la tinción de Gram. 
Para la identificación molecular de los actinomicetos se extrajo el ADN utilizando el DNeasy Plant Mini Kit ${ }^{\mathrm{MR}}$ (Qiagen Inc.) y se amplificó por PCR utilizando los iniciadores 8F (5'agagtttgatcctggctcag-3') y 1492R (5'-ggttaccttgttacgactt-3') (Sacchi et al., 2002). Las reacciones de amplificación se llevaron a cabo en un termociclador Thermo ${ }^{\mathrm{MR}}$, las cuales consistieron en una desnaturalización a $94{ }^{\circ} \mathrm{C}$ por $1 \mathrm{~min}$, seguido por 35 ciclos a $94{ }^{\circ} \mathrm{C}$ por $30 \mathrm{~s}$, un anillamiento a 48 ${ }^{\circ} \mathrm{C}$ por $50 \mathrm{~s}$ y una extensión a $72{ }^{\circ} \mathrm{C}$ por $80 \mathrm{~s}$ y una extensión final a $72{ }^{\circ} \mathrm{C}$ por $4 \mathrm{~min}$. Los productos se visualizaron por electroforesis en gel de agarosa al $1 \%$ teñido con $0.5 \mathrm{ng}^{-1} \mathrm{l}^{-1}$ de bromuro de etidio. Se utilizó el marcador de peso molecular ladder-100 ${ }^{\mathrm{MR}}$ (Axygen).

\section{Caracterización morfológica y genética de los hongos con actividad antagónica}

La identificación morfológica de los aislados obtenidos estuvo basada en las características de las colonias (color, tipo y forma) además de la morfología de conidios y conidióforos utilizando un microscopio óptico (Úrbaez et al., 2013). Además, se realizaron montajes en laminillas utilizando el colorante lactofenol azul de algodón como solución, y se describieron las características particulares de las estructuras. Los hongos se identificaron siguiendo los criterios de Barnett y Hunter (1998); Phillips et al. (2013).

Para la caracterización genética, se extrajo el ADN genómico a partir de micelio siguiendo las instrucciones del fabricante del kit DNeasy Plant Mini Kit ${ }^{\mathrm{MR}}$ (Qiagen Inc.). El ADN se cuantificó con un espectrofotómetro Take $3^{\mathrm{MR}}$ (Bioselec). Se amplificó por PCR la región ITS-1, el gen ribosomal 5.8S y el ITS-2 utilizando los iniciadores ITS-1 fu 5 'tccgtaggtgaacctgcgg-3' e ITS-4 5'tcctccgcttatttgatatgc-3' (White et al., 1990). Las reacciones de amplificación se llevaron a cabo en un termociclador Termo ${ }^{\mathrm{MR}}$, las cuales consistieron en una desnaturalización a $94{ }^{\circ} \mathrm{C}$ por $1 \mathrm{~min}$, un anillamiento a $55^{\circ} \mathrm{C}$ por $25 \mathrm{~s}$, una polimerización a $72^{\circ} \mathrm{C}$ durante $50 \mathrm{~s}$, con 35 ciclos, seguido de una extensión final a $72^{\circ} \mathrm{C}$ por 4 min. Los productos de PCR fueron secuenciados y comparados con secuencias del GenBank para confirmar la identidad de las cepas a nivel de especie.

\section{Prueba de antagonismo in vitro}

Se realizó una prueba preliminar para seleccionar las cepas que presentaran mayor efecto inhibitorio sobre los hongos patógenos. Las confrontaciones se realizaron con cada cepa de los microorganismos aislados contra los hongos fitopatógenos L. theobromae y F. meliae. Se sembró una azada de cada uno de los microorganismos en los cuatro puntos cardinales $(3 \mathrm{~cm}$ de distancia del centro, en cajas Petri) en el medio PDLMA. Cuarenta y ocho horas después un explante de 0.5 $\mathrm{cm}$ de crecimiento de cada hongo fitopatógeno fue colocado en el centro. Las cajas fueron incubadas a $25 \pm 2{ }^{\circ} \mathrm{C}$ durante 5 días. Cada microorganismo se tomó como un tratamiento con tres repeticiones, considerando cada caja Petri como una repetición y un control negativo con cada hongo sin antagonista. El ensayo se realizó dos veces.

La capacidad inhibitoria de los microorganismos se cuantificó midiendo el diámetro del crecimiento fúngico con un vernier, usando dos diámetros cardinales previamente dibujados en la parte baja de cada caja Petri como referencia.

El porcentaje de inhibición fue calculado usando la siguiente fórmula: $(\%)$ de inhibición = [(A1A2)/A1] x 100. Donde: A1= crecimiento de la colonia del fitopatógeno (testigo); A2 = crecimiento de la colonia fungosa del fitopatógeno creciendo frente al actinomiceto. 
Con base a los resultados de las pruebas preliminares de las confrontaciones in vitro, se seleccionaron las cepas M1-101 y M104 para un segundo ensayo por presentar los valores más altos de inhibición. Las cepas antagonistas fueron cultivadas en caldo papa dextrosa adicionado con extracto de levadura y extracto de malta al $0.3 \%$ (CPDLM), e incubadas a $25 \pm 2{ }^{\circ} \mathrm{C}$ y 125 rpm durante 10 días. Posteriormente, el contenido fue centrifugado, filtrado y colocado en frascos estériles.

La actividad de inhibición de cada antagonista fue evaluada a concentraciones de 25, 50 y $100 \%$ del filtrado. La técnica consistió en esparcir por extensión $100 \mu l$ del antagonista. Posteriormente, fue colocado un disco de $5 \mathrm{~mm}$ del crecimiento micelial del fitopatógeno en el centro de la caja Petri. Además, se confrontó cada antagonista con los dos hongos fitopatógenos al mismo tiempo, para lo cual se esparcieron $100 \mu \mathrm{l}$ del antagonista por el método de extensión en cajas e inmediatamente un disco del crecimiento micelial de cada hongo de $5 \mathrm{~mm}$ de diámetro fue colocado a una distancia de $4 \mathrm{~cm}$ entre ellos. Se realizaron observaciones diarias durante cinco días, al final de los cuales se midió el crecimiento micelial de los hongos, cuando el crecimiento del control cubrió por completo la caja Petri.

\section{Inhibición de la germinación de conidios y micelio}

Con base en los resultados preliminares se seleccionó la cepa M1-101 para la prueba de inhibición de la germinación de conidios y micelio de los hongos $F$. meliae y L. theobromae, respectivamente. La cepa M1-101 se sembró en $50 \mathrm{ml}$ de caldo CPDLM mediante la adición de un cuadro de la cepa en agar de aproximadamente $1 \mathrm{~cm}^{2}$ por cada matraz Erlenmeyer bafleado de $250 \mathrm{ml}$. Los matraces se incubaron en agitación a $125 \mathrm{rpm}$ y $25 \pm 2{ }^{\circ} \mathrm{C}$ durante 10 días. Al término del periodo de incubación, se filtró al cultivo y el filtrado se diluyó hasta tener concentraciones de 25, 50 y $100 \%$.

Para la preparación del inóculo de los hongos fitopatógenos se usaron cepas incubadas por 6 días en papa dextrosa agar (PDA). Se agregaron $10 \mathrm{ml}$ de agua destilada estéril a cada caja Petri para resuspender los conidios de $F$. meliae y el micelio de $L$. theobromae raspando la superficie de la caja con un asa bacteriológica. El inoculo se conservó en tubos cónicos de $15 \mathrm{ml}$.

La actividad de inhibición de la germinación del antagonista fue evaluada a concentraciones de 25 , 50 y $100 \%$. La técnica consistió en extender con ayuda de un asa de vidrio, $100 \mu 1$ de cada concentración en cada caja Petri. Después de absorción, se añadieron $100 \mu \mathrm{l}$ del inoculo de los fitopatógenos de la solución previamente preparada (conidios y micelio) de los fitopatógenos. Se evaluaron tres réplicas de cada concentración y las cajas Petri se incubaron a $25 \pm 2{ }^{\circ} \mathrm{C}$. Cada $24 \mathrm{~h}$ se realizaron observaciones para ver la inhibición de la germinación de conidios y los posibles cambios en la morfología del micelio.

El recuento de conidios germinados y no germinados fue realizado usando un microscopio compuesto (Leica DM500). Se contabilizaron 100 conidios $\mathrm{cm}^{-2}, 500$ conidios en total (germinados y no germinados). Para determinar el porcentaje de conidios germinados se utilizó la siguiente fórmula: \% germinación $=(\mathrm{a} / \mathrm{a}+\mathrm{b})$ x 100 . Donde: $\mathrm{a}=$ número de conidios germinadas; $\mathrm{y} \mathrm{b}=$ número de conidios sin germinar. Con L. theobromae, sólo se observaron los cambios en la morfología del micelio inducido por la presencia de los compuestos antifúngicos, producidos por el antagonista a un nivel microscópico. 


\section{Resultados}

Se aislaron 70 cepas de microorganismos de las cuales 15 presentaron actividad inhibitoria, y de estas, ocho presentaban características típicas de actinobacterias, cinco bacterias bacilares y dos hongos (Cuadro 2).

Cuadro 2. Microorganismos aislados de suelo de diferentes zonas del estado de Nuevo León con actividad antagónica.

\begin{tabular}{ccc}
\hline Cepas & Lugar de muestreo & Clasificación \\
\hline A7 & Mina & Bacilo \\
A14 & Mina & Bacilo \\
A18 & Mina & Bacilo \\
A20 & Mina & Bacilo \\
A23 & Mina & Bacilo \\
CH 102 & La Ascensión & Actinomiceto \\
CH 103 & La Ascensión & Actinomiceto \\
M 104 & Marín & Hongo \\
M1-101 & Marín & Actinomiceto \\
M2 R1 & Mina & Actinomiceto \\
M2 R2 & Mina & Actinomiceto \\
M3 & Marín & Actinomiceto \\
M4 & Marín & Actinomiceto \\
M4 R & Mina & Actinomiceto \\
M5-102 & Marín & Hongo \\
\hline
\end{tabular}

\section{Caracterización morfológica y genética de los actinomicetos y bacterias bacilares}

Las características de crecimiento colonial de los actinomicetos en cultivo fueron masas aéreas secas, polvosas, con bordes irregulares, de pigmentaciones variadas, observándose tonalidades de color amarillo, gris y otras de color anaranjado. Al microscopio (40X) mostraron las ramificaciones típicas de los actinomicetos. Por tinción Gram se observaron estreptobacilos esporulados Gram positivos.

Las bacterias mostraron tonalidades variables como amarillo y crema (Figura 1), con textura acuosa y bordes regulares. Mediante tinción Gram se observaron bacilos Gram positivos y Gram negativos. No se logró la identificación molecular de las cepas de actinomicetos por una falta de amplificación por PCR atribuida posiblemente a que los iniciadores o primers han sido más utilizados con otras bacterias y tal vez no tengan la especificidad suficiente para unirse a las secuencias de actinomicetos. 


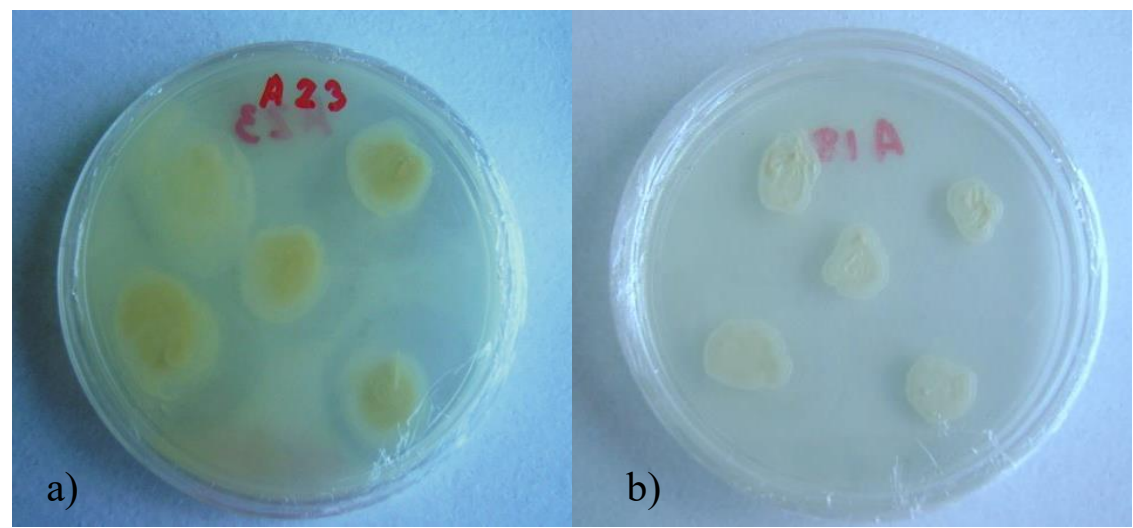

Figura 1. Bacterias aisladas del suelo. a) cepa A23 mostrando halo de inhibición; y b) cepa A18.

Las bacterias bacilares obtenidas fueron amplificadas por PCR y se secuenció parte del gen 16S. Las secuencias consenso de las bacterias bacilares fueron comparadas con secuencias depositadas en el GenBank a través del programa Blast; la cepa A18 correspondió a Achromobacter xylosoxidans con un $96 \%$ de homología y A23 mostró 96\% de similitud con Delftia sp.

\section{Caracterización morfológica y genética de los hongos con actividad antifúngica}

Las colonias de la cepa M104 en medio de cultivo fueron de color blanco, compactas y con bordes irregulares, y el micelio de la cepa M5-102 de color café (Figura 2). La cepa M104 fue identificada como Penicillium sp. Las características del conidióforo mostraban forma de escobilla y conidios hialinos, unicelulares en forma cilíndrica. La cepa M5-102 presentó conidióforos y cabezas aspergilar, conidios hialinos, unicelulares y cilíndricos; esta cepa fue identificada como Aspergillus sp. La identificación morfológica fue confirmada por su secuencia de ADN, correspondiendo a Penicillium citrinum y Aspergillus sp.

\section{Prueba de antagonismo in vitro}

Acromobacter xylosoxidans redujo el crecimiento micelial de L. theobromae $63 \%$ y a $F$. meliae $59 \%$. Por otro lado, Delftia sp. inhibió en un 39\% a ambos hongos fitopatógenos. Aspergillus sp., redujo $82 \%$ el crecimiento de $L$. theobromae y a $F$. meliae en $83 \%$. La cepa identificada como $P$. citrinum fue capaz de reducir el crecimiento micelial de L. theobromae en $83 \%$ manteniéndolo inhibido durante más 20 días. Los valores más altos de inhibición se obtuvieron con el hongo $P$. citrinum (M104) y acinomicetos M4R, y M1-101, los cuales mostraron porcentajes de inhibición de 85,84 y $91 \%$ contra $L$. theobromae y 91,83 , y $91 \%$, contra $F$. meliae respectivamente.

En la prueba de inhibición con las diferentes concentraciones de los filtrados del actinomiceto y $P$. citrinum $(25,50$ y 100\%), hubo diferencias estadísticamente significativas $(p<0.001)$ en el porcentaje de inhibición de los patógenos. El control presentó el crecimiento micelial más alto a los 5 días, después de que los hongos se colocaron en PDA. Los hongos L. theobromae y F. meliae tuvieron un crecimiento similar, no mostrando diferencias significativas entre ellos. Los tratamientos que mostraron mayor inhibición de los patógenos fueron $L$. theobromae y $F$. meliae frente a $P$. citrinum al $100 \%$, seguido por $L$. theobromae $+P$. citrinum y $F$. meliae $+P$. citrinum con la concentración al 100\%. No hubo diferencias entre las tres concentraciones de la cepa M101 
contra $F$. meliae. En la prueba de inhibición con las diferentes concentraciones de los filtrados del actinomiceto y $P$. citrinum $(25,50$ y $100 \%)$, hubo diferencias estadísticamente significativas $(p=$ 0) en el porcentaje de inhibición de los patógenos.
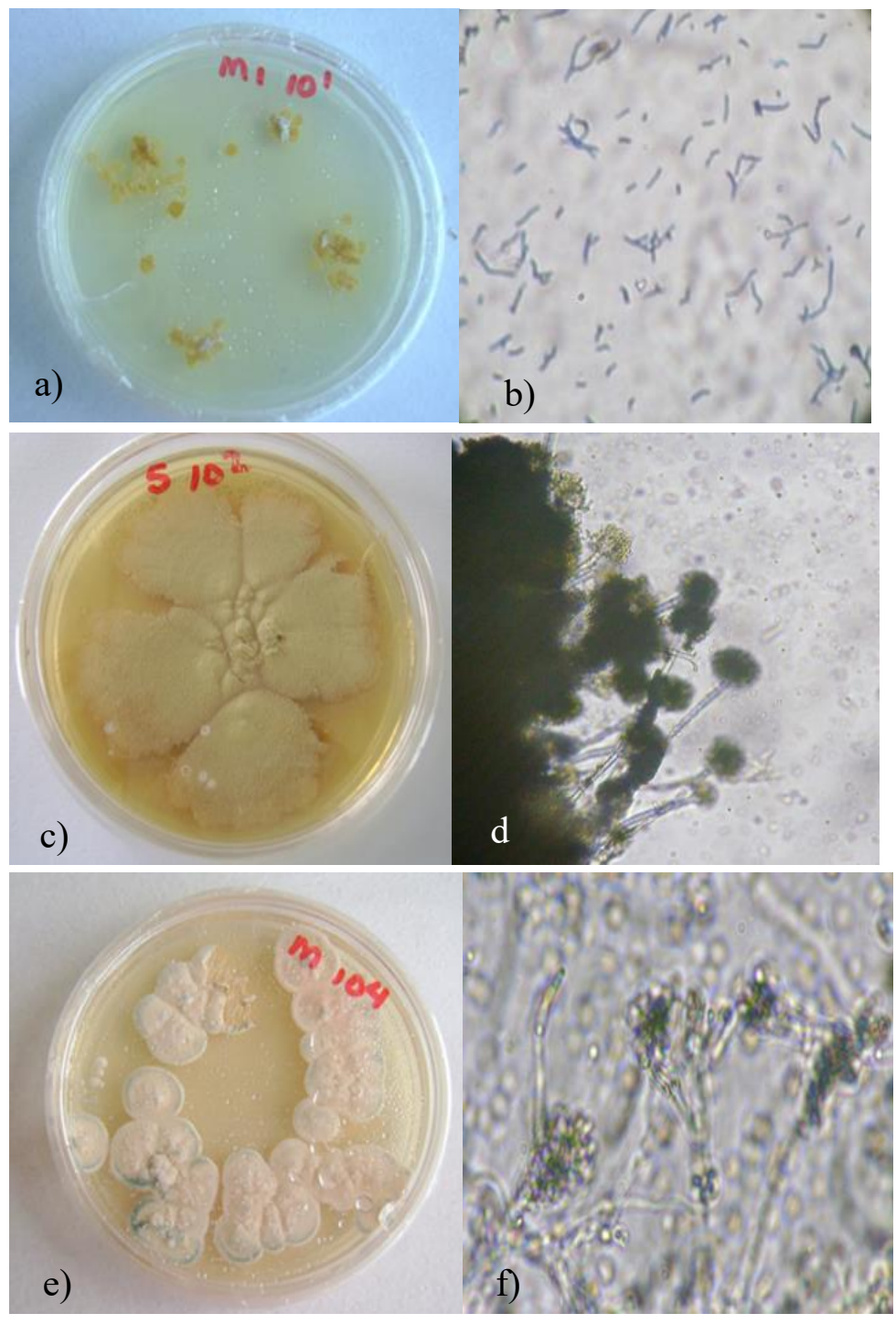

Figura 2. Microorganismos con actividad antifúngica. a) colonias de la cepa M1-101 en PDA; b) bacilos Gram positivos observados al microscopio; c) cepa M5-102 en PDA; d) conidióforos y cabezas aspergilar de Aspergillus sp.; e) cepa M104 en PDA; y F) conidióforos, fiálide y conidias de $P$. citrinum.

\section{Inhibición de la germinación de conidios}

L. theobromae a las 96 h de incubación cubrió por completo la caja Petri sin obtenerse ninguna estructura reproductiva. Sin embargo, en presencia del antagonista, L. theobromae produjo clamidosporas de color café oscuro y células conidiógenas (Figura 3). Con la confrontación, los conidios de $F$. meliae son inhibidos y no fueron capaces de germinar, se observó que los conidios se agrupan y engrosan tendiendo a formar clamidosporas (Figura 3). 


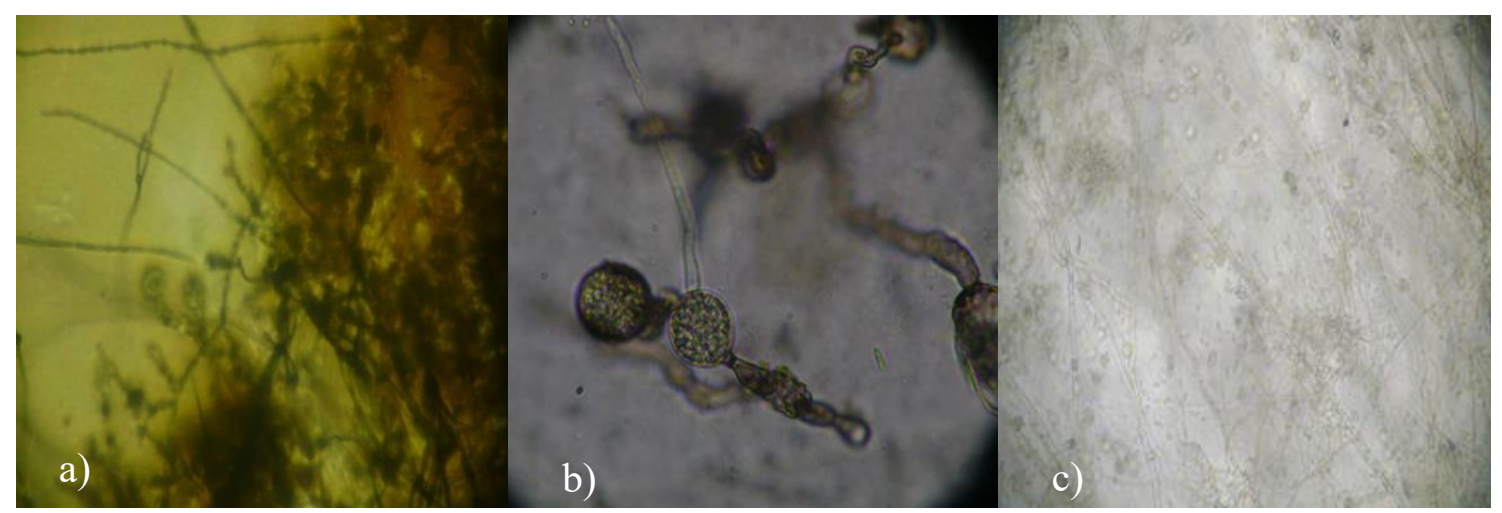

Figura 3. Crecimiento de $L$. theobromae bajo condiciones de confrontación. a) células conidiógenas; b) y c) clamidosporas.

\section{Discusión}

En este estudio la bacteria A. xylosoxidans fue efectiva en reducir el crecimiento in vitro de $L$. theobromae y $F$. melie. La capacidad que presentó esta bacteria de biocontrolar estos patógenos es comparable con los resultados reportados por Moretti et al. (2008), quienes usaron esta bacteria para controlar a Fusarium oxysporum causante del marchitamiento del tomate. Bagheri y Ahmadzadeh (2016) también reportaron que A. xylosoxidans puede inhibir a Curvularia lunata y Bipolaris sorikinian presentes en el cultivo de trigo.

Por otro lado, algunas especies del género Delftia han sido reportadas por Han et al. (2005) inhibiendo a Xanthomonas oryzae pv. oryzae, Rhizoctonia solani y Pyricularia oryzae. Adicionalmente, estas bacterias desempeñan un papel importante en tecnologías de biorremediación (Ubalde et al., 2012). Jergensen et al. (2009) citan a Delftia con capacidad de romper los enlaces glicosídicos en la quitina y los péptidoglucano, con lo cual pudieran mostrar mayor capacidad de inhibición de los hongos fitopatógenos como los usados en este estudio.

Por lo general, las especies del género Aspergillus están consideradas como hongos saprófitos u oportunistas (Cortés y Mosqueda, 2013). Algunas razas de Aspergillus sp., son consideradas como atoxigénicas debido a que no producen aflatoxinas y han sido registradas como cepas biocontroladoras, cuyo mecanismo de acción es la exclusión competitiva (Cotty, 1994). Debido a esas cualidades, una cepa de Aspergillus fue formulada y ha sido comercializada como agente de biocontrol de la especie Aspergillus flavus productora de aflatoxinas (Dorner, 2009).

En este estudio, Aspergillus sp. fue capaz de inhibir el crecimiento de L. theobromae y F. meliae. Estos resultados son confirmados por los hallazgos obtenidos por Adeniyi et al. (2013) quienes reportaron a A. niger como agente biocontrolador de L. theobromae, aunque sugieren que se debe explotar su potencial en otros fitopatógenos y manejar los posibles efectos adversos en los cultivos.

A pesar de que el hongo $P$. citrinum puede causar enfermedades en cultivos en campo y productos postcosecha (Marquardt, 1996), de acuerdo con nuestros resultados, algunas especies de Penicillium también poseen potencial de inhibir patógenos. Estos resultados pueden ser explicados de acuerdo con Quiroz et al. (2008), quienes reportaron que diferentes especies de hongos poseen mecanismos tanto de antagonistas como patógenos. 
De las 15 cepas que se aislaron y evaluaron, los actinomicetos mostraron los valores más altos de inhibición (M4 R y M1-101), siendo M1-101 la cepa con mayor actividad antagónica, con porcentajes de inhibición contra $L$. theobromae y $F$. meliae de 84 y $91 \%$, respectivamente. Sánchez et al. (2011); Wang et al. (2015) aislaron actinomicetos con capacidad de inhibir a fitopatógenos de importancia agrícola como Fusarium equiseti.

Los resultados obtenidos en este estudio demuestran que la habilidad de los microorganismos para inhibir patógenos puede ser incrementada o disminuida, dependiendo de las condiciones de las estructuras de sobrevivencia que puedan producir los últimos y que el antagonista logra reducir su crecimiento por la producción de compuestos antifúngicos o exclusión competitiva.

\section{Conclusiones}

Se logró el aislamiento de actinomicetos a partir de muestras de suelo, capaces de inhibir el crecimiento de los patógenos causantes de la muerte regresiva de los cítricos L. theobromae y $F$. meliae. Las cepas M4R y M104 presentaron porcentajes de inhibición superiores a 84\% contra los fitopatógenos anteriores.

Los hongos Aspergillus sp. y $P$. citrinum fueron capaces de reducir el crecimiento de L. theobromae y $F$. meliae. Por la capacidad antagonista demostrada en el presente estudio, las cepas de actinomicetos M4R y M104 y los hongos Aspergillus sp. y P. citrinum podrían ser considerados como potenciales candidatos a ser utilizados en programas de control de L. theobromae y F. meliae, pero se necesita continuar con los estudios de esta capacidad antagónica in vivo.

\section{Literatura citada}

Abdallah, M. E.; Haroun, S. A.; Gomah, A. A.; El-Naggar, N. E. and Badr, H. H. 2013. Application of actinomycetes as biocontrol agents in the management of onion bacterial rot diseases. Archives of Phytopathology and Plant Protection. 46(15):1797-1808. http://dx.doi.org/10.1080/03235408.2013.778451.

Adeniyi, D. O.; Adedeji, A. R.; Oduwaye, O. F. and Kolawolw, O. O. 2013. Evaluation of biocontrol agents against Lasiodiplodia theobromae causing inflorescence blight of cashew in Nigeria. Journal of Agriculture and Veterinary Science. 5(3):46-48.

Adesemoye, A. O.; Mayorquin, J. S.; Wang, D. H.; Twizeyima, M.; Lynch, S. C. and Eskalen, A. 2014. Identification of species of Botryosphaeriaceae causing bot gummosis in citrus in California. Plant Disease. 98(1):55-61. http://dx.doi.org/10.1094/PDIS-05-13-0492-RE.

Álvarez, L. A. 2015. Eficacia fungicida en el control de Lasiodiplodia theobromae en plantas de palto (Persea americana) con el uso del bioestimulante a base de algas Fertimar. Plagas y Enfermedades. VIII Congreso Mundial de la Palta 135-140. www.wacperu2015.

Badii, M. H. y Abreu, J. L. 2006. Control biológico una forma sustentable de control de plagas. International Journal of Good Conscience. 1(1):82-89.

Bagheri, N. and Ahmadzadeh, M. 2016. First report of Acromobacter xyloxidans on wheat rhizosphere in Iran and its biocontrol activity. Scientia Agriculturae. 16(1):36-42, DOI: 10.15192/PSCP.SA.2016.16.1.3642.

Barnett, H. L. and Hunter, B. B. 1998 Illustrated Genera of Imperfect Fungi. The American Phytophatological Society. Minnesota. $4^{\text {ta. }}$ Ed. 217 p. 
Carisse, O.; El Bassam, S. and Benhamou, N. 2001. Effect of Microsphaeropsis sp. strain P130A on germination and production of sclerotia of Rhizoctonia solani and interaction between the antagonism and the pathogen. Phytopathology. 91(8):782-791. https://doi.org/10.1094/PHYTO.2001.91.8.782.

Caro, C. J.; Mateo, T. C.; Cisneros, M. J.; Galindo, C. N. y León, Q. J. 2019. Aislamiento y selección de actinomicetos rizosféricos con actividad antagonista a fitopatógenos de la papa (Solanum tuberosum spp. andigena). Ecología Aplicada. 18(2):101-109. http://dx.doi.org/10.21704/rea.v18i2.1329.

Cheng, C. H., Yang, C. A. and Cheng, P. K. 2012. Antagonism of Trichoderma harzaianum ETS 323 grown in the presence of deactivated Botrytis cinerea mycelium in culture conditions. Phytopathology. 102(11):1054-1063. https://doi.org/10.1094/PHYTO-11-11-0315.

Cortés, S. A. D. y Mosqueda, O. T. 2013. Una mirada a los organismos fúngicos: Fábricas versátiles de diversos metabolitos secundarios de interés biotecnológico. Revista Química Viva. 12(2):64-90. http://www.redalyc.org/articulo.oa?id=86328550002.

Cotty, P. J. 1994. Influence of field application of an atoxigenic strain of Aspergillus flavus on the populations of $A$. flavus infecting cotton bolls and on the aflatoxin content of cotton seed. Phytopathology. 84(11):1270-1277. Doi: 10.1094/Phyto-84-1270.

Dávila, M. M. D.; Gallegos, M. G.; Hernández, C. D.; Ochoa, F. Y. M. y Flores, O. A. 2013 Actinomicetos antagónicos de importancia agrícola. Rev. Mex. Cienc. Agríc. 4(8):1187-1196.

Dorner, J. W. 2009. Biological control of aflatoxin contamination in corn using a nontoxigenic strain of Aspergillus flavus. Journal of Food Protection. 72(4):801-804.

Han, J.; Sun, L.; Dong, X.; Cai, Z.; Sun, X.; Yang, H.; Wang, Y. and Song, W. 2005. Characterization of a novel plant growth-promoting bacteria strain Delftia tsuruhatensis HR4 both as a diazotroph and a potential biocontrol agent against various plant pathogens. Systematic and Applied Microbiology. 28(1):66-76. Doi:10.1016/j.syapm.2004.09.003.

Jergensen, N. O. G.; Brandt, K. K.; Nybroe, O. and Hansen, M. 2009. Delftia lacustris sp. nov., a peptidoglycan-degrading bacterium from fresh water, and emended description of Delftia tsuruhatensis as a peptidoglycan degrading bacterium. International Journal of Systematic and Evolutionary Microbiology. 59(9):2195-2199. Doi:10.1099/ijs.0.008375-0.

Kamil, F. H.; Saeed, E. E.; El-Tarabily, K. A. and AbuQamar, S. F. 2018. Biological control of mango dieback disease caused by Lasiodiplodia theobromae using streptomycete and nonstreptomycete actinobacteria in the United Arab Emirates. Frontiers in Microbiology. 9(829):1-19. Doi: 10.3389/fmicb.2018.00829.

Lee, C. H.; Kim, B. J.; Choi, G. J.; Cho, K. Y.; Yang, H.; Shin, C.; Min, S. and Lim, Y. 2002. Streptomyces with antifungal activity against rice blast causing fungus Magnaporte grisea. Journal of Microbiology and Biotechnology.12(6):1026-1028.

Lerma, C. J.; Ibarra, T. A.; Galván, G. V.; Martínez, D. J.; Rodríguez, R. G.; Tellez, G. V.; Fernández, S. C.; Núñez; G. M. y Galicia, C. J. 2015. Situación de la citricultura en Nuevo León. Corporación para el Desarrollo Agropecuario de Nuevo León. OEIDRUS, N. L. Washington 2000. 82 p.

Marquardt, R. R. 1996. Effects of molds and their toxins on livestock performance: a western Canadian perspective. Animal Feed Science and Technology. 58(1-2): 77-89. Doi:10.1016/0377-8401(95)00875-6.

Moretti, M.; Giladi, G.; Gullino, M. L. and Garibaldi, A. 2008. Biological control of Achromobacter xylososydans for suppressing Fusarium wilt of tomato. International Journal of Botany. 4(4):369-375. Doi:10.3923/ijb.2008.369.375. 
Mutawila, C.; Fourie, P. H., Halleen, F. and Mosteri, L. 2011. Grapevine cultivar variation to prunnin wound protection by Trichoderma species against trunk pathogens. Phytopahology Mediterranea. 50(supplement):274-276.

Orozco, S. M.; Robles, G. M.; Velázquez, M. J. J.; Manzanilla, R. M. A.; Hernández, F. L. M.; Manzo, S. G. y Nieto, A. D. 2013. Manejo integrado de las principales plagas y enfermedades en limón mexicano y limón persa. Memorias IX Simposio Internacional Citrícola. 113-171 pp.

Oskay, M.; Usame, T. A. and Azeri, C. 2004. Antibacterial activity of some actinomycetes isolated from farming soils of Tuley. African Journal of Biotechnology. 3(9):441-446, http://dx.doi.org/10.1016/j.funbio.2016.06.004.

Phillips, A. J. L.; Alves, A.; Abdollahzadeh, J.; Slippers, B.; Wingfield, M. J.; Groenewald, J. Z. and Crous, P. W. 2013. The Botryosphaeriaceae: genera and species known from culture. Studies in Micology. 76:51-167. doi:10.3114/sim0021.

Polanco, F. L. G.; Alvarado G. O. G.; Pérez, G. O.; González, G. R. y Olivares, S. E. 2019. Hongos asociados con la muerte regresiva de los cítricos en Nuevo León y Tamaulipas, México. Rev. Mex. Cienc. Agríc. 10(4):757-764.

Quiñones, A. E. E.; Evangelista, M. Z. y Rincón. E. G. 2016. Los actinomicetos y su aplicación biotecnológica. Elementos. 101:59-64.

Quiroz, S. V. F.; Ferrera, C. R.; Alarcón, A. y Lara, H. M. E. 2008. Antagonismo in vitro de cepas de Aspergillus y Trichoderma hacia hongos filamentosos que afectan al cultivo de ajo. Revista Mexicana de Micologia. 26:27-34.

Rodríguez, G. E; Guerrero, P.; Barradas, C., Crous, P. W. and Alves, A. 2016. Phylogeny and pathogenicity of Lasiodiplodia species associated with dieback of mango in Peru. Fungal Biology. 121(4):452-465. http://dx.doi.org/10.1016/j.funbio.2016.06.004.

Sacchi, C.T.; Whitney, A. M.; Mayer, L. W.; Morey, R.; Steigerwalt, A.; Boras, A.; Weylant, R. S. and Popovie. 2002. Sequencing of 16S rRNA gene: A rapid tool for the identification of Bacillus anthracis. Emerging Infectious Disease. 8(10):1117-1122. Doi:10.3201/eid0810.020391.

Sajitha, K. L. and Florence, E. J. M. 2013. Effects of Streptomyces sp. on growth of Rubbergood Sapstain fungus Lasiodiplodia theobromae. Journal of Tropical Forest Science. 25(3):393-399.

Sánchez, O. M. R.; Sánchez, P. S. R.; Gallegos, M. G. y Sánchez, A. A. 2011. Actividad inhibitoria de actinomicetos aislados de hormigas cultivadoras de hongos (Hymenoptera:Formicidae) sobre Colletotrichum lindemuthianu, y Rhizoctonia solani. Revista Agraria. 8(1):14-17.

Sreevidya, M. and Gopalakrishnan, S. 2012. Bacteria and actinomycetes as biocontrol agents for the control of fungal of chickpea and sorghum. International Crops Research Institute for the Semi Arid Tropics. 293 p.

Tovar, P. J. M.; Mora, A. J. A.; Nava, D. C.; Téliz, O. D.; Villegas, M. A. and Leyva, M. S. G. 2013. Control of Lasiodiplodia theobromae, the causal agent of dieback of sapote mamey [Pouteria sapota (Jacq.) H. E. Moore and Stern] grafts in Mexico. Revista Fitotecnia Mexicana. 36(3):233-238. http://www.redalyc.org/articulo.oa?id=61028975007.

Ubalde, M. C.; Braña, V.; Sueiro, F. M.; Morel, A.; Martínez, R. C.; Marquez, C. and Castro, S. S. 2012. The iof Delftia sp. isolates as tools for bioremediation and biofertilization technologies. Current Microbiology. 64(6):597-603.

Úrbaez, T. J. R.; Peduto, F.; Vossen, P. M.; Krueger, W. H. and Gubler, W. D. 2013. Olive twig and branch dieback: etiology, incidence and distribution in California. Plant Disease. 97(12):23-244. http://dx.doi.org/10.1094/PDIS-04-12-0390-RE. 
Wang, L.; Xing, M.; Di, R. and Luo, Y. 2015. Identification and antifungal activities of Streptomyces aureoverticillatus HN6. Journal of Plant Pathology and Microbiology. 6:281-286. http://dx.doi.org/10.4172/2157-7471.1000281.

White, T. J.; Bruns, T.; Lee, S. and Taylor, J. 1990. PCR Protocols: A guide to methods and applications. Academic Press. San Diego, CA. 322 p. 